\title{
O CLIMA URBANO DE SÃO JOÃO DE MERITI/RJ: UM ESTUDO APLICADO À ANÁLISE DO CAMPO TÉRMICO E ILHAS DE CALOR
}

\author{
Leandro da Silva Gregório 3 \\ Ana Maria P. Macedo Brandão 4
}

\begin{abstract}
RESUMO
A degradação ambiental tornou-se centro das atenções devido aos estudos do IPCC sobre o aquecimento global. Porém as manifestações das transformações do clima se dão primeiramente nas escalas menores; uma dessas manifestações nesta escala são as ilhas de calor, comuns nos grandes centros urbanos. A Região Metropolitana do Rio de Janeiro é um exemplo da grande intervenção antrópica no ambiente e a exemplo de outras metrópoles, possui inúmeros problemas ambientais cujos impactos tem sido agravados ano após ano, principalmente, no que diz respeito à intensificação das ilhas de calor. Dentre os municípios da Região metropolitana destaca-se São João de Meriti que é o município de maior densidade demográfica do Brasil. Este município é exemplo de degradação ambiental dos mais alarmantes. Apresenta altíssimo grau de urbanização, quase $90 \%$, e elevadíssimos níveis de poluição do ar. Este trabalho é pioneiro no estudo sobre ilhas de calor neste município. Tem como objetivo fazer uma análise do campo térmico no município de São João de Meriti, buscando encontrar indícios de ilhas de calor através de experimentos de campo e com o uso do sensor termal do Satélite Landsat 5.
\end{abstract}

Palavras chaves: Clima Urbano, Ilhas de calor, sensoriamento remoto, Qualidade Ambiental

\begin{abstract}
The environmental degradation is the attention of center nowadays because the studies of IPCC about climate changes. But, the manifestations of climate changes happens first in minor scales, one this manifestations in this scale are the heat islands. This work has as objective to make an analysis of the thermal

${ }^{3}$ Geógrafo Mestrando do Programa de Pós Graduação em Geografia da Universidade Federal do Rio de Janeiro, Rio de Janeiro -RJ.e-mail:mikadishen@hotmail.com

${ }^{4}$ Géografa, Profa. Dra Adjunta, Depto. Geografia, Universidade Federal do Rio de Janeiro, Rio de Janeiro-RJe-mail:anabrandao@globo.com
\end{abstract}


field in the city of They are João de Meriti, searching to find indications of heat islands through experiments of field and with the use of the thermal sensor of the Satellite Landsat 5. One searchs, still, to evaluate the influence of the behavior of the thermal field in the discomfort to the heat of the population.

Key Words: Urban Climate, Heat Islands, Remote Sensing, Enviromental Quality

\section{INTRODUÇÃO}

A intensidade e recorrência de problemas urbanos de natureza climática, como as ilhas de calor, tem sido a tônica dessas últimas décadas. Inegavelmente, estes problemas trazem conseqüências danosas, afetando a saúde física e mental da população que vive nos centros urbanos, que somados a outros impactos ambientais, contribuem para uma diminuição da qualidade de vida das pessoas.

Algumas características dos centros urbanos, como a substituição de áreas verdes por área construída, dificulta a infiltração das águas pluviais no solo, acarretando em alagamentos e enchentes em chuvas intensas. Com a redução de áreas verdes, o calor fica "aprisionado" no espaço intra-urbano e com altura cada vez maior dos prédios formando verdadeiros "canyons" urbanos prejudicando a livre circulação dos ventos, há um favorecimento a formação de ilhas de calor e uma menor dispersão dos poluentes proveniente do fluxo de veículo. Dentre os municípios da Baixada Fluminense destaca-se o município de São João de Meriti, área de estudo específica deste estudo, que concentra um contingente populacional de 449.476 habitantes numa restrita área de apenas $35 \mathrm{~km}^{2}$, resultando na maior densidade demográfica do Brasil $12946 \mathrm{hab} / \mathrm{km}^{2}$ (IBGE, 2000). Além disso, o município possui uma área quase $100 \%$ urbanizada, decorrente do seu intenso processo de urbanização com nenhum resquício de mata nativa e com poucas áreas arborizadas. Estas são algumas características que contribuem para o grave estado de degradação sócioambiental em São João de Meriti. Este trabalho objetiva fazer uma análise do campo térmico no município de São João de Meriti, buscando encontrar indícios de ilhas de calor através de experimentos de campo e com o uso do sensor termal do Satélite Landsat 5. Busca-se, ainda, avaliar a influência do comportamento do campo térmico no desconforto ao calor da população.

\section{METODOLOGIA}

A metodologia deste trabalho consistiu do Levantamento bibliográfico sobre o tema e o município; levantamento de dados, informações e documentos referentes ao município; coleta de dados climáticos disponíveis para o município; uso do software Excel para tratamento estatístico dos dados e elaboração dos respectivos gráficos; monitoramento de campo para obtenção de dados climáticos de temperatura e umidade relativa do ar em diferentes ambientes, utilizando-se para isto de "data loggers". Os experimentos de campo foram realizados nas estações de inverno de 2006, entre os dias 29 de julho e 04 de agosto e de verão de 2007, durante o período de 16 de fevereiro a 19 de 
março. Tentou-se, ainda, monitoramento na estação de primavera, porém devido a problemas técnicos, excluímos tais dados da análise. Para o tratamento e análise dos dados utilizaram-se o software Arc View 3.2 para elaboração do Modelo Numérico de Terreno (MNT) da temperatura, o qual foi obtido por meio do interpolador IDW (Inverso do quadrado da distância) e a grade regular retangular.

Com o intuito de confrontar a verdade terrestre (dos dados mensurados em campo) com as informações de temperatura aparente registrada por sensor orbital, foi feita uma comparação dos dados de temperatura obtidos pelo equipamento em campo no dia $11 / 03 / 2007$ às 10:00 AM com o imageado pelo sensor termal (banda 6) LandSat 5 TM. Para o tratamento dessas informações utilizou-se o Sistema de Processamento de Informações Georeferenciadas (SPRING) desenvolvido pelo Instituto Nacional de Pesquisas Espaciais (INPE). Como resultado foram elaborados uma carta-imagem e um mapa de uso do solo do município de São João de Meriti utilizando-se das bandas 3, 4 e 5 para geração da composição colorida e posterior classificação para geração do mapa de uso do solo, com o objetivo de correlacionar os tipos de uso no município com os valores de temperatura.

$\mathrm{Na}$ imagem termal para a obtenção da temperatura aparente foi exigida a transformação do sinal digital proveniente do satélite em radiância, o qual foi convertido em temperatura como descrito por Chander e Markhann (2000) pelas fórmulas a seguir:

$$
\begin{gathered}
L=\left\{\left[\left(L_{\max }-L_{\min }\right) /\left(N C_{\max }-N C_{\min }\right)\right]^{*}\left(N C-N C_{\min }\right)\right\}+L_{\min } \\
\operatorname{Temp}\left({ }^{\circ} C\right)=\left\{k_{1} /\left[\ln \left(k_{2} / L\right)+1\right\}-273,15\right.
\end{gathered}
$$

onde:

Lmax e LMin representam, respectivamente, os valores da radiância máxima e mínima escalonados pelo sensor;

NCmax e NCmin representam, respectivamente, os níveis de cinza máximo e mínimo;

NC representa o nível de cinza de cada pixel da imagem; banda 6.

k1 $(1260,56)$ e $\boldsymbol{k} \mathbf{2}(607,76)$ são as constantes de calibração para a

\section{RESULTADOS E DISCUSSÕES}

O "município "de São João de Meriti localiza-se a 22047'48" de latitude S e a 43023'48" de longitude $O$, sendo um dos treze municípios que formam a região da Baixada Fluminense a qual se insere na Região Metropolitana do Rio de Janeiro

O sítio (figura1) da Região é bastante diversificado com a ocorrência de áreas baixas predominando estas nos municípios de Duque de Caxias e Magé; os morrotes, também conhecidos como "morros meia-laranja" que ocorrem em grande parte da região, destacando-se o município de São João de Meriti, com 34 km² e mais de 40 elevações acima de 100 metros. Elevações médias em Nilópolis e Belford Roxo, crescendo à medida que atinge Queimados e Japerí. 
Ao Norte da Região localizam-se as vertentes da Serra do Mar e o maciço do Tinguá, onde se encontram as maiores elevações do território, próximas de 1700 metros de altitude. No Sul encontra-se outra elevação, o Maciço que é também chamado de Serra de Madureira ou, mais recentemente, Serra do Vulcão. Neste, o ponto mais alto chega a 974 metros (Figura 1).

Nas várias planícies existentes, que em geral acompanham os rios, ocorrem constantes inundações, formando brejos e alagados, principalmente à medida que se aproximam da Baía de Guanabara. A expansão da Baixada fluminense ocorreu juntamente com a expansão da cidade do Rio de Janeiro nos séculos XVIII e XIX.

O município de São João de Meriti teve seus primeiros povoamentos no século XVII e seu auge econômico aconteceu no século XVIII devido aos inúmeros engenhos existentes e ao intenso transporte de produtos alimentícios nos rios através dos portos fluviais que cortavam a região.

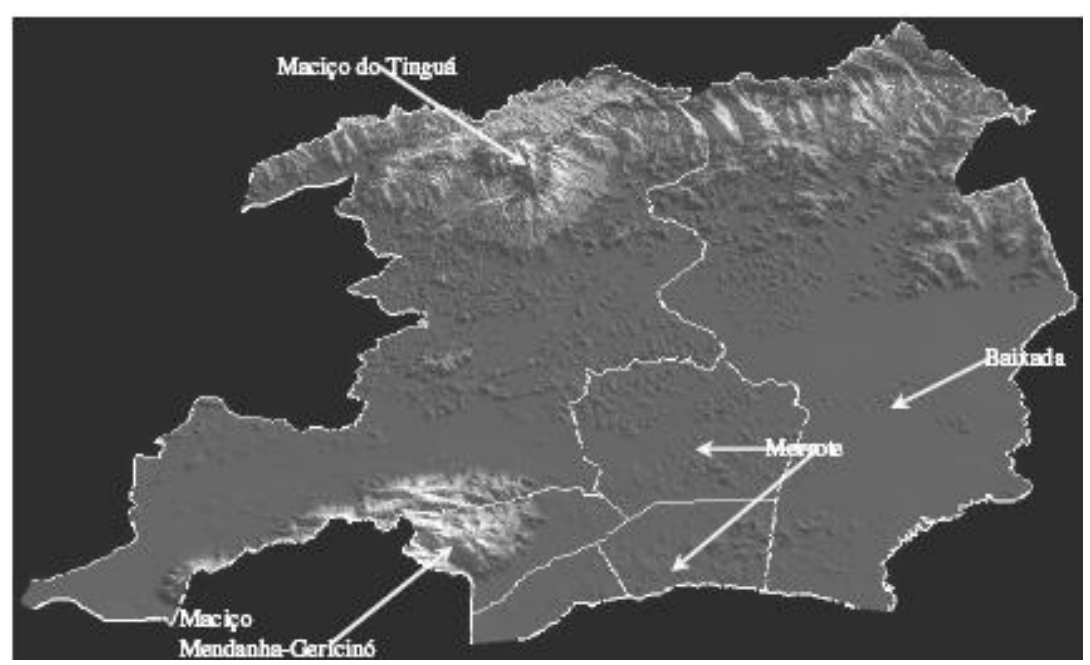

Figura 1. Modelo Numérico de Terreno do Relevo de parte da Baixada Fluminense.

Este período de prosperidade começou a entrar em decadência a partir do século XIX. Vários fatores de ordem física, econômica, política e social contribuíram para isto. De ordem física podemos dizer que o desenvolvimento da agricultura levou a uma drástica alteração do ambiente com a derrubada da mata nativa para dar lugar ao plantio e ao pasto para o gado e para extração de lenha. Com isso, os rios Meriti e Sarapuí, que eram navegáveis até meados do século XIX, devido ao desmatamento nas cabeceiras e margens provocaram a obstrução dos cursos d'água; o matagal cobriu extensas áreas dos rios; o leito turfado transformou-se em pântano (TORRES, 2004). A navegação foi prejudicada impedindo o escoamento da produção através dos rios. Além disso, em 1855, a região foi atingida por uma febre, chamada cólera-morbus, pela malária e pelo impaludismo, doenças atribuídas ao desmatamento das margens e assoreamento dos rios. (TORRES, 2004).

Entretanto é no século XX, principalmente, a partir dos anos 30 e 40 que São João de Meriti passou pelas maiores transformações em seu espaço geográfico desde a sua fundação no século XVI cujos efeitos permanecem até hoje como degradação dos rios, a pouca vegetação existente, a precária infra- 
estrutura urbana (figura 2), além da grande densidade de construção de forma desordenada, chegando o grande crescimento populacional do município a expressar-se na maior densidade demográfica do Brasil, com 12479 hab/Km² (gráfico 1).

Com estas características os impactos no clima local se manifestam de forma bastante expressiva no município, demonstrado, por exemplo, pelos elevados índices de poluição no município e as ilhas de calor.

Grafico1. Evolução do crescimento da população meritiense. Fonte dos dados: CIDE e IBGE.
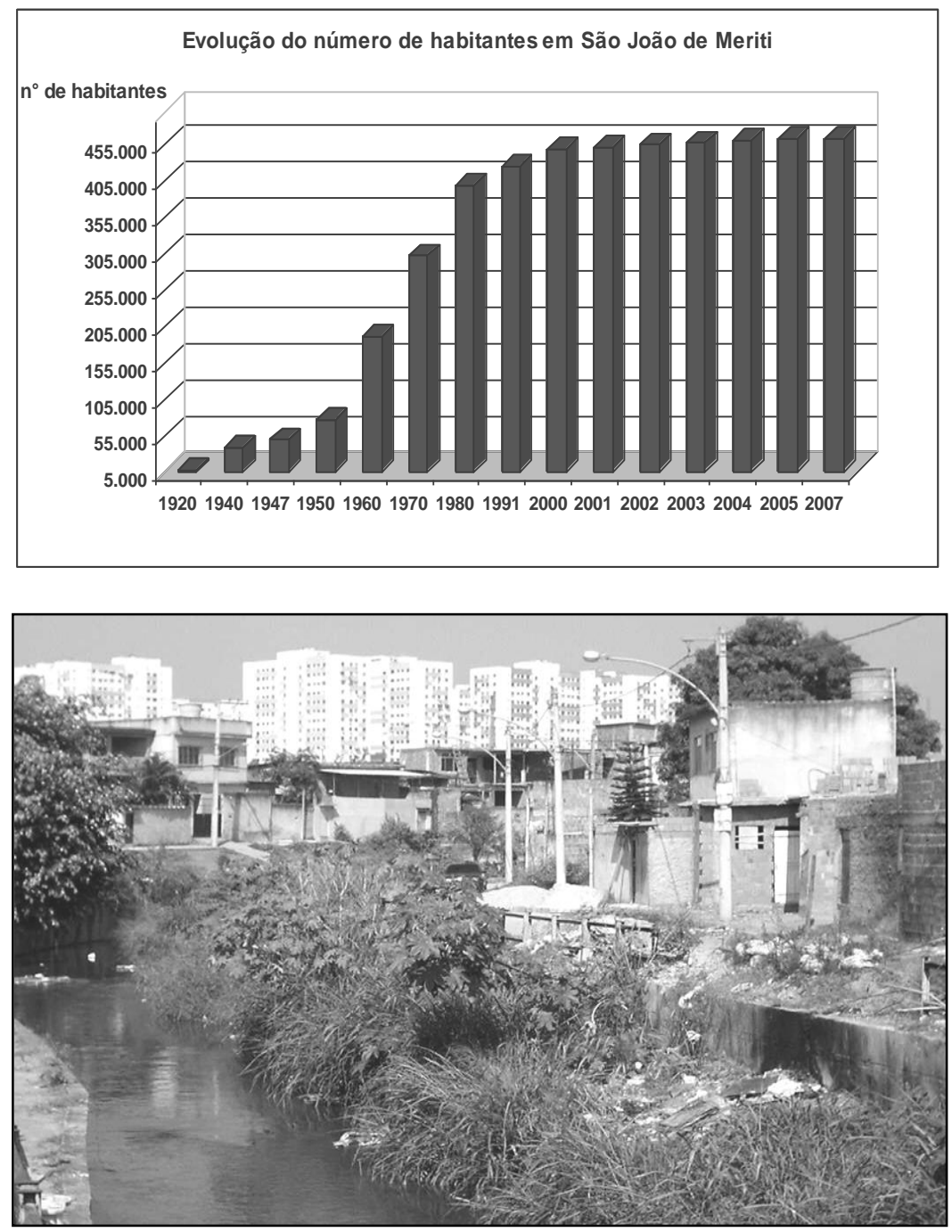

Figura 2. Foto Rio Pavuna Fonte: Arquivo pessoal dos autores.

No Rio de Janeiro, o clima urbano é estudado desde a década de 80 por BRANDÃO (1987, 1996), onde ficou demonstrado claramente como as transformações antrópicas na cidade e na região metropolitana do Rio de Janeiro contribuíram para elevar a temperatura da cidade desde os anos de 
1950 e para a configuração do clima local, ocorrendo, por exemplo, ilhas de calor de forte intensidade em situações sinóticas favoráveis.

Estudar o clima urbano local é de grande importância, pois nas menores escalas que ocorrem as maiores transformações no espaço geográfico e, conseqüentemente, as alterações do clima são mais evidenciadas, pois as derivações na atmosfera pela ação antrópica se dão, justamente, das escalas inferiores para as superiores (MONTEIRO, 1978).

Antes de entrar na análise do clima urbano propriamente dito e, mais especificamente, do campo térmico de São João de Meriti, torna-se necessário abordar alguns conceitos importantes para a melhor compreensão das alterações que se processam nos elementos do clima, especialmente a temperatura do ar, em função das derivações antrópicas resultantes do processo de urbanização-industrialização.

Monteiro (1976), ao propor o modelo teórico para a abordagem do clima urbano, considerado como sistema dinâmico-adaptativo, admite dez enunciados básicos, acompanhados de comentários, como idéias reguladoras aos estudos do sistema clima urbano. Como primeiro enunciado, destaca que o clima urbano deve ser definido como o clima de um dado espaço incluindo sua urbanização. Portanto, está implícita a análise integrada do fato natural (o clima local) e do fato social (a cidade). A partir daí, entende-se que a compreensão do clima urbano só poderá ser alcançada considerando as características geoecológicas da cidade e os atributos urbanos. Em outras palavras, os aspectos físicos, entre eles o clima, agem de modo a influenciar o lugar (a cidade) e, por outro lado, há um certo grau de alteração do clima da cidade imposto pelo novo ambiente urbanizado (a cidade). Considerando que a urbanização é o processo de conversão do meio físico (natural) para o assentamento humano, acompanhado de drásticas e irreversíveis mudanças do uso do solo, tal processo gera uma nova configuração da superfície aerodinâmica e das propriedades radiativas, da umidade e da qualidade do ar nesse ambiente transformado que é a cidade. Como resultado a estrutura vertical da atmosfera urbana revela significativos contrastes quando comparada com a atmosfera rural. (BRANDÃO, 1996).

Segundo Oke (1980) a parcela da baixa atmosfera urbana, aquela cujas características são comandadas pela superfície urbana, se diferencia entre a parcela que sofre a ação direta do conjunto heterogêneo de arranjos e combinações entre atributos geoecológicos, topográficos, de edificação e funções urbanas, cujo limite vai da superfície até o nível dos telhados dos prédios (urban canopy layer) e aquela cuja base é o nível dos telhados (urban boundary layer).

Isto significa que todo esse aparato implantado na cidade (indústrias, trânsito intenso, concentração de edifícios, equipamentos e pessoas, solo impermeável, novas formas topográficas, substituição da cobertura vegetal por superfícies asfaltadas, entre outros) resulta na produção de calor artificial que perturba significativamente o ar intra-urbano. As influências da urbanização no clima da cidade podem ser sintetizadas em três categorias principais: modificação da composição do ar, alteração do equilíbrio térmico e do balanço hídrico. Uma espécie de cúpula climática é gerada na cidade, denominada clima urbano, cujas peculiaridades dependem do tamanho e desenho da cidade, da densidade das construções e das funções urbanas, das características dos materiais utilizados nas construções e da própria configuração da cidade e das atividades que nela se desenvolvem. Todo esse processo de alteração nos 
atributos do clima em escala local reflete sobre o real papel do homem e de sua obra na cidade como agente de derivação ambiental e gerador do clima urbano. Recentemente o tema vem despertando, cada vez mais interesse de geógrafos, entre outros estudiosos, principalmente, no tocante ao campo térmico (configuração de ilhas de calor), ao impacto pluvial (enchentes) e a qualidade do ar (poluição) e seus impactos na qualidade de vida dos citadinos. (BRANDÃO, 2001).

Este estudo aborda o assunto relacionado ao campo térmico no município de São João de Meriti, que talvez seja um dos maiores exemplos de intervenção antrópica no ambiente natural, visto seu enorme adensamento populacional, densidade de construção, concentração industrial e grande circulação de veículos, carência de vegetação e inúmeros outros problemas de ordem sócioambiental. Este município, a despeito de toda esta problemática urbana, até então não havia despertado o interesse para pesquisas na linha de investigação do clima urbano e, mais especificamente, o campo térmico e a configuração de ilhas de calor urbana, por isso se tornou alvo desta investigação. A pesquisa do campo térmico, ora apresentada, se deu pela realização de experimentos de campo no inverno de 2006 e verão de 2007, seguindo metodologia proposta por Monteiro (1976) e Brandão (1996).

A análise climática na escala do urbano (escala local), buscando compreender as relações dos fatos termodinâmicos do ar dentro da cidade associadas com os fatos específicos da própria condição urbana requer algumas condições imprescindíveis para apontar resultados que, no mínimo, conduzam a novas hipóteses que possibilitam avançar na investigação de um fato tão complexo como aquele que a cidade enseja. Uma recomendação básica é que a observação-mensuração dos elementos do clima esteja referenciada a observação meteorológica padrão local e referenciada aos tipos de tempo mais expressivos que a circulação atmosférica regional condiciona localmente.

A ausência de algumas condições importantes ao bom desempenho da pesquisa no município de São João de Meriti, felizmente, não impossibilitaram sua execução, mas exigiu algumas manobras ou adaptações para não comprometer os resultados pretendidos. O fato mais grave diz respeito à ausência de, pelo menos, uma estação meteorológica localizada nos limites administrativos do município, fato este, associado à dificuldade de obtenção de dados e informações em geral, especialmente, os relacionados aos aspectos históricos, exigindo um árduo trabalho de "garimpagem" dos pesquisadores.

Mediante essa carência foi tomado como referencia para a análise do clima urbano de São João de Meriti a estação climatológica Ecologia Agrícola, do Instituto Nacional de Meteorologia (INMET) que está localizada no município de Seropédica, no campus da Universidade Federal Rural do Rio de Janeiro (figura 3), que dispõe de uma longa série histórica, desde o ano de 1939.

Apesar de não estar nas adjacências do município, esta estação foi escolhida, pois é a mais próxima de São João de Meriti e está em um contexto geográfico semelhante ao do município, como sitio de baixada e elevada taxa de urbanização. 


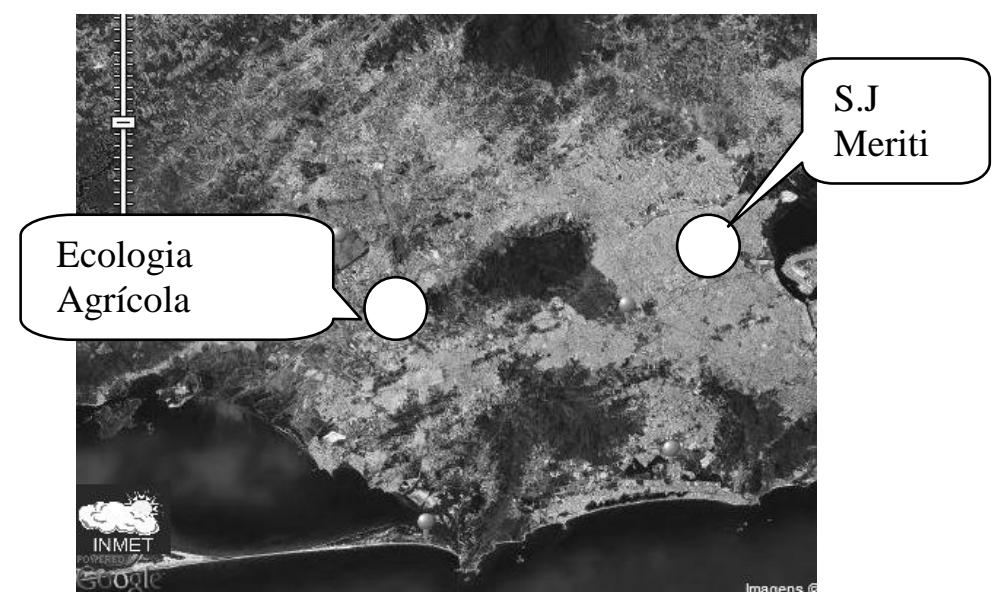

Figura 3. Localização da Estação Ecologia Agrícola.

Para tentar caracterizar a evolução e a tendência da temperatura na região, visando detectar uma possível relação entre comportamento térmico e evolução urbana, foram analisados os dados de temperatura média anual (compensada, máxima e mínima) do período de 1940 a 2000, elegendo-se como exemplo, o gráfico da temperatura mínima por apresentar resultados mais relevantes. (gráfico 2). Observa-se neste gráfico, mesmo considerando uma variabilidade temporal esperada para um elemento de natureza dinâmica como a temperatura do ar, um aspecto peculiar, destacando-se uma clara tendência de aumento da temperatura no período, a qual pode ser visualizada pela linha da média móvel.

Gráfico 2. Evolução e tendência da temperatura mínima. Fonte dos dados: INMET

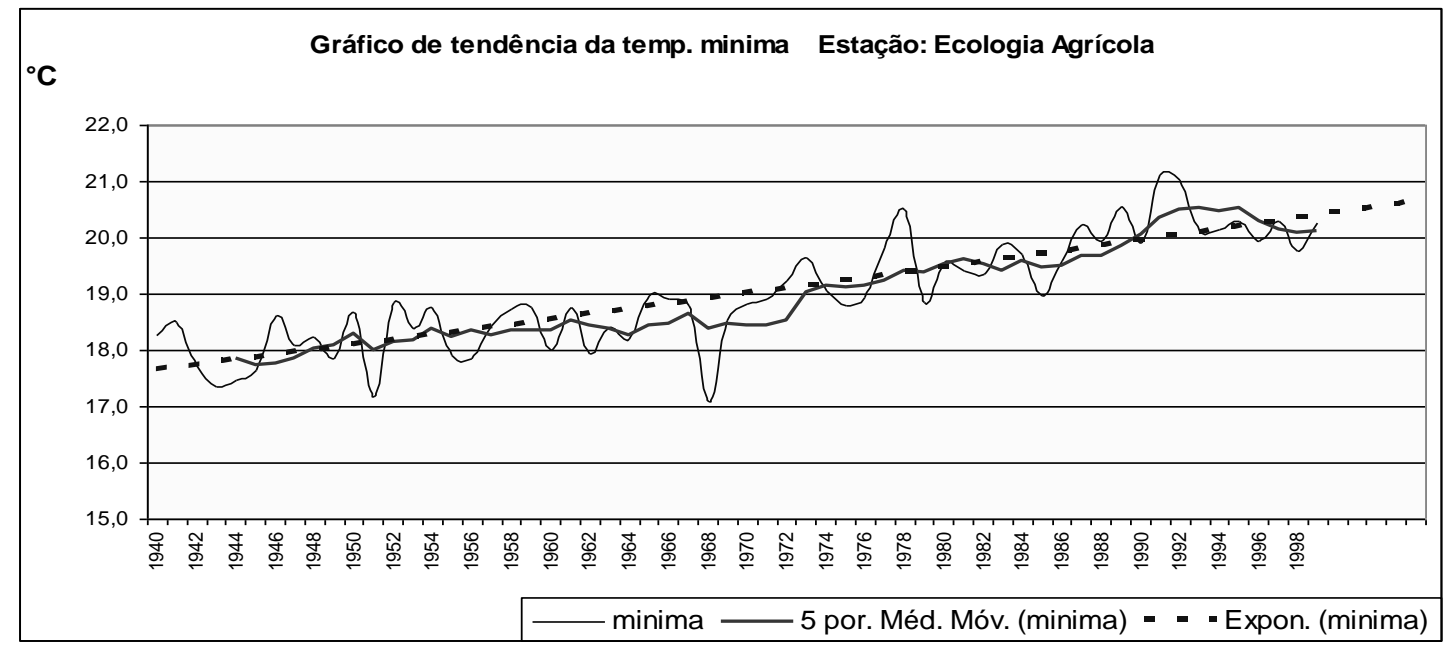

Outro aspecto importante é visualizado pela simples comparação dos dados registrados, sobretudo entre as primeiras décadas do período (1940 e 1950) cujas temperaturas mínimas médias anuais se situaram entre 17 e $19^{\circ} \mathrm{C}$ contra as décadas finais do período, sobretudo as de 1980 e 1990, cujas mesmas temperaturas oscilaram entre 19 e $21^{\circ}$ C e com médias anuais 
predominantemente acima da média do período, portanto acusando significativo aumento de temperatura. Mais precisamente os anos da década de 1960 marcam essa mudança para um período com temperaturas bem mais elevadas, coincidentemente, década que marca uma fase de grande expansão da urbanização, não só nessa região como na cidade do Rio de Janeiro. Sem exagero pode-se extrapolar essa informação para São João de Meriti, onde ocorreu processo semelhante ou mais intenso, fato que pode ser comprovado pela taxa de urbanização que é maior e onde a degradação ambiental é mais crítica que em Itaguaí, onde se situa a Estação Ecologia Agrícola.

Para suprir a carência de dados climáticos e para atender a exigência necessária para contemplar a diversidade e multiplicidade da investigação do clima no espaço urbano, foi necessário projetar a multiplicação dos pontos de observação na área de estudo.

Assim, montou-se uma estrutura para realização de experimentos de campo a nível episódico, para análise do comportamento da temperatura no município. Foram realizados dois trabalhos de campo, um no ano de 2006, na estação de inverno e um no verão de 2007. A duração dos trabalhos de campo para a tomada de dados, por problemas circunstanciais, não teve a mesma duração. O experimento do inverno de 2006 teve duração de sete dias (de 29 de julho a 04 de agosto), enquanto o do verão de 2007, teve duração prolongada para cinco semanas (de 16 de fevereiro a 19 de março). Em ambos foi utilizado o termo-higrômetro automático (data loggers) da marca Novus. Em função de problemas técnico-operacionais relacionados ao monitoramento de campo realizado na estação de primavera de 2006, a decisão mais recomendada foi à exclusão desses dados nas análises.

Do experimento de campo de inverno foi tomado como exemplo para apresentação do campo térmico, o dia 26 de junho por revelar condições atmosféricas mais favoráveis à manifestação da ilha de calor devido ao predomínio do anticiclone subtropical do atlântico, céu claro e pouca nebulosidade antecedendo a aproximação de um sistema frontal.

Os horários que apresentaram as maiores temperaturas nesse dia, foram 12:00h (figura 4) e 15:00h (figura 5) com temperaturas oscilando entre 24 e $27^{\circ} \mathrm{C}$ e os locais mais quentes em ambos horários foram os bairros do centro de São João de Meriti e de Vilar dos Teles, que se configuraram como core da ilha de calor nesses horários. Entretanto as ilhas de calor do inverno de 2006 não se manifestaram de forma espetacular, classificando-se como de fraca e moderada intensidades (de $1^{\circ}$ a $2^{\circ} \mathrm{C}$ ), influenciada pela aproximação de um sistema frontal que não favoreceu a uma maior intensidade da ilha de calor.

Já no experimento realizado no verão de 2007 (gráfico 3), por problemas de segurança só foi possível a realização das mensurações de dados em dois pontos, um localizado no bairro de São Mateus, próximo ao centro de São João de Meriti e outro no município de Belford Roxo. Entretanto o período de mensuração estendeu-se por cinco semanas como citado anteriormente.

Ao longo das cinco semanas de monitoramento a temperatura apresentou valores bastante altos em ambos os pontos, porém elas foram mais elevadas em São João de Meriti que em Belford Roxo. 


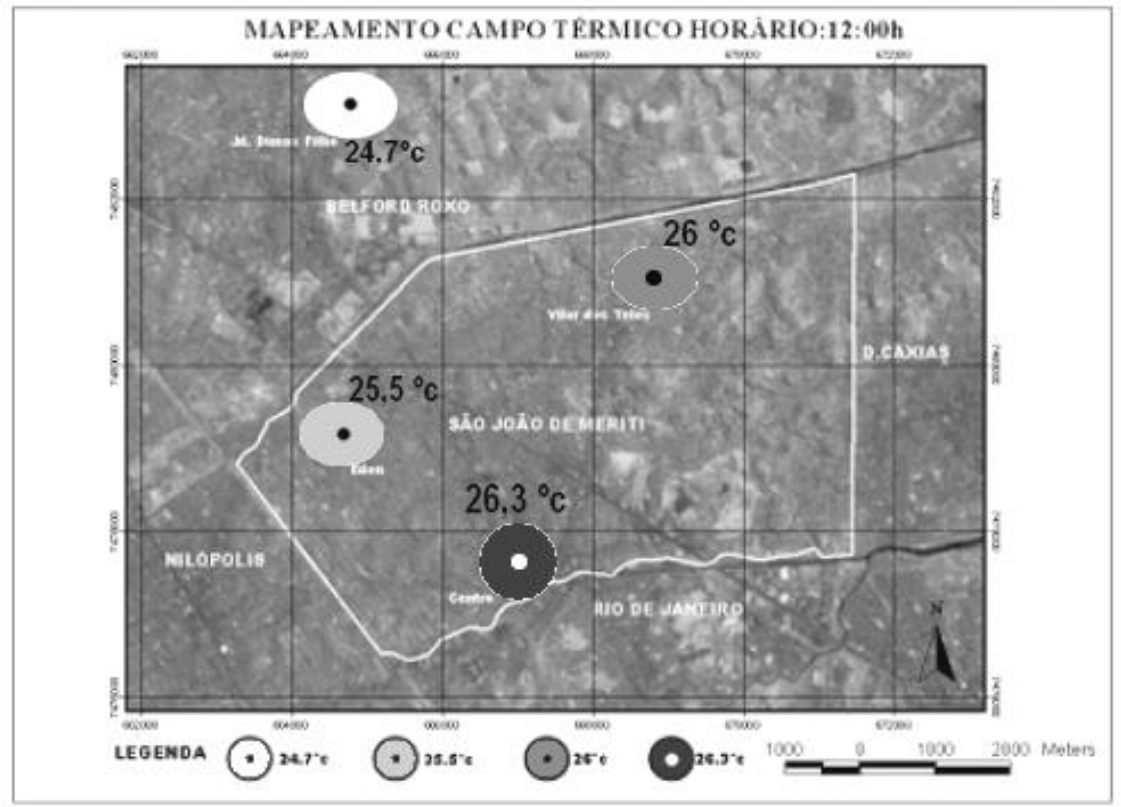

Figura 4. Campo Térmico no experimento de inverno de 2006 as 12:00

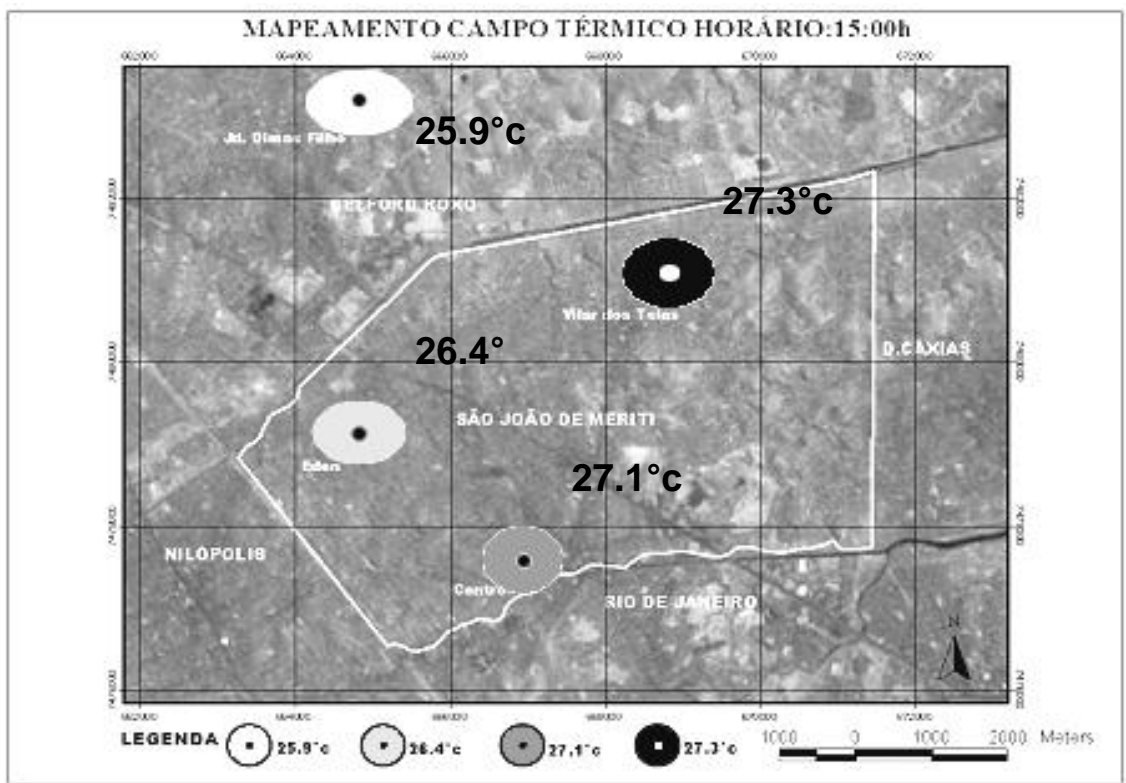

Figura 5. Campo Térmico no experimento de inverno de 2006 as 15:00

Para efeito de ilustração, será apresentado o gráfico 3 onde se visualiza os dados térmicos registrados durante a quarta semanas de monitoramento nos dois pontos de amostra. O destaque em círculo correspondente ao dia 10 de março às 14:00, pelos valores absolutos mais elevados de todo o período de registro ( $38^{\circ} \mathrm{C}$ em Belford Roxo e $42^{\circ} \mathrm{C}$ em São João), uma diferença de $5^{\circ} \mathrm{C}$ entre essas duas localidades. Tais dados sugerem que a configuração de uma ilha de calor é de média a forte intensidade na área central de São João de 
Meriti em comparação com o bairro de Belford Roxo nesse horário. Ao contrário, a temperatura mais baixa ocorreu às 6 horas da manhã, oscilando em torno de $26^{\circ} \mathrm{C}$ em Belford Roxo e de $27^{\circ} \mathrm{C}$ em São João. A umidade relativa do ar, também apresentou grande variação no período e comportamento semelhante, embora com valores um pouco mais elevados e maiores amplitudes em São João de Meriti. A condição sinótica de verão, caracterizada por grande estabilidade atmosférica, garantida pela atuação do anticiclone subtropical do atlântico favoreceu a manifestação mais intensa da ilha de calor. Isto reforça a importância de se considerar a análise do contexto sinótico regional.

Gráfico 3. Comparação dos pontos utilizados no experimento de verão de 2007 pelos autores.
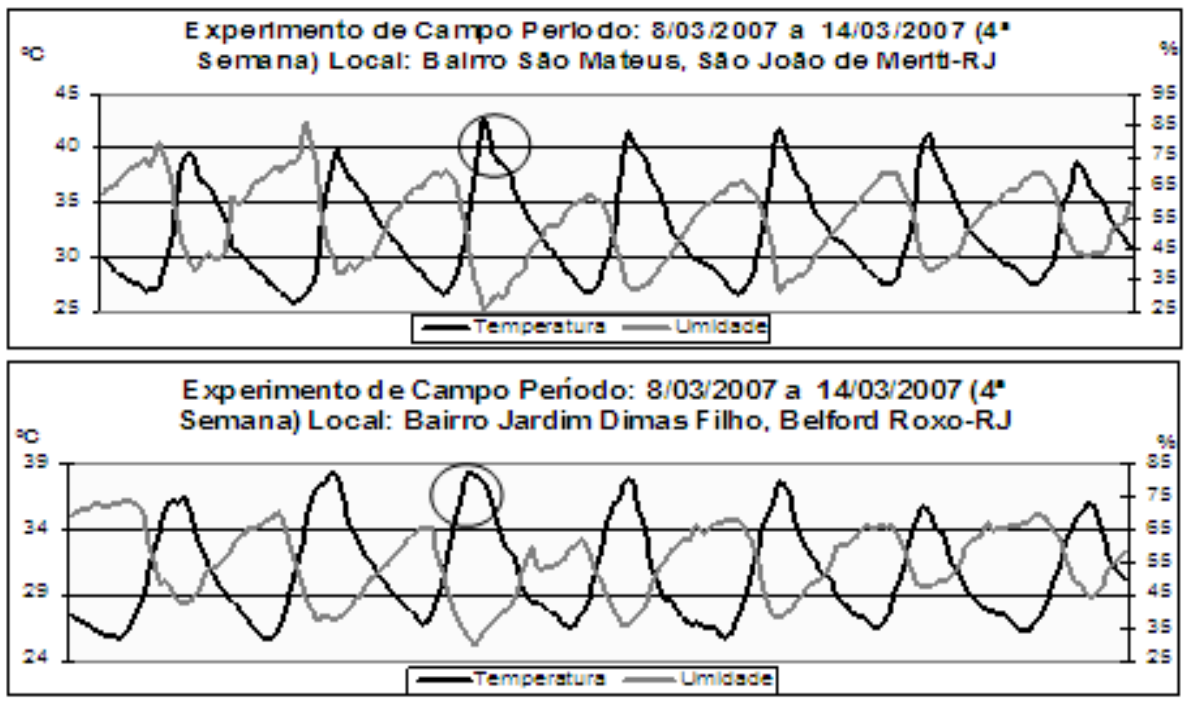

Com o intuito de confrontar a verdade terrestre dos dados mensurados no campo com as informações de temperatura aparente mensurada por sensor orbital, foi realizada uma comparação dos dados de temperatura obtidos em superfície pelo "data logger" no dia 11/03/2007 às 10:00 AM com o imageado pelo sensor termal (banda 6) do satélite LandSat 5 TM.

No tratamento das informações foi utilizado o Sistema de Processamento de Informações Georeferenciadas (SPRING) desenvolvido pelo Instituto Nacional de Pesquisas Espaciais (INPE). Para isto elaborou-se carta-imagem e mapa de uso do solo da área de estudo (figuras 6 e 7 ), o que demandou o uso das bandas 3, 4 e 5 para inicialmente a geração da composição colorida e posterior classificação para geração do mapa de uso do solo. Esta etapa é necessária e útil a fim de permitir correlacionar os tipos de uso no município com os valores de temperatura obtidos. Os mapas de uso do solo da Fundação Centro de Informação e Dados do Rio de Janeiro (CIDE) consultados, o nível de detalhe da escala não atendeu as necessidades de nosso trabalho, pelo critério de generalização adotado. Como exemplo cita-se o caso do município estar classificado como área $100 \%$ urbanizada, pois os fragmentos de vegetação não aparecem na escala. Por essa razão foi elaborado um mapa de uso do solo em escala adequada para expressar um nível de detalhe maior para atender a correlação pretendida. Assim, em uma escala maior os fragmentos de vegetação 
puderam ser considerados, e como resultado a área urbana foi quantificada em $75 \%$ e a área de vegetação foi estimada em $21,5 \%$.

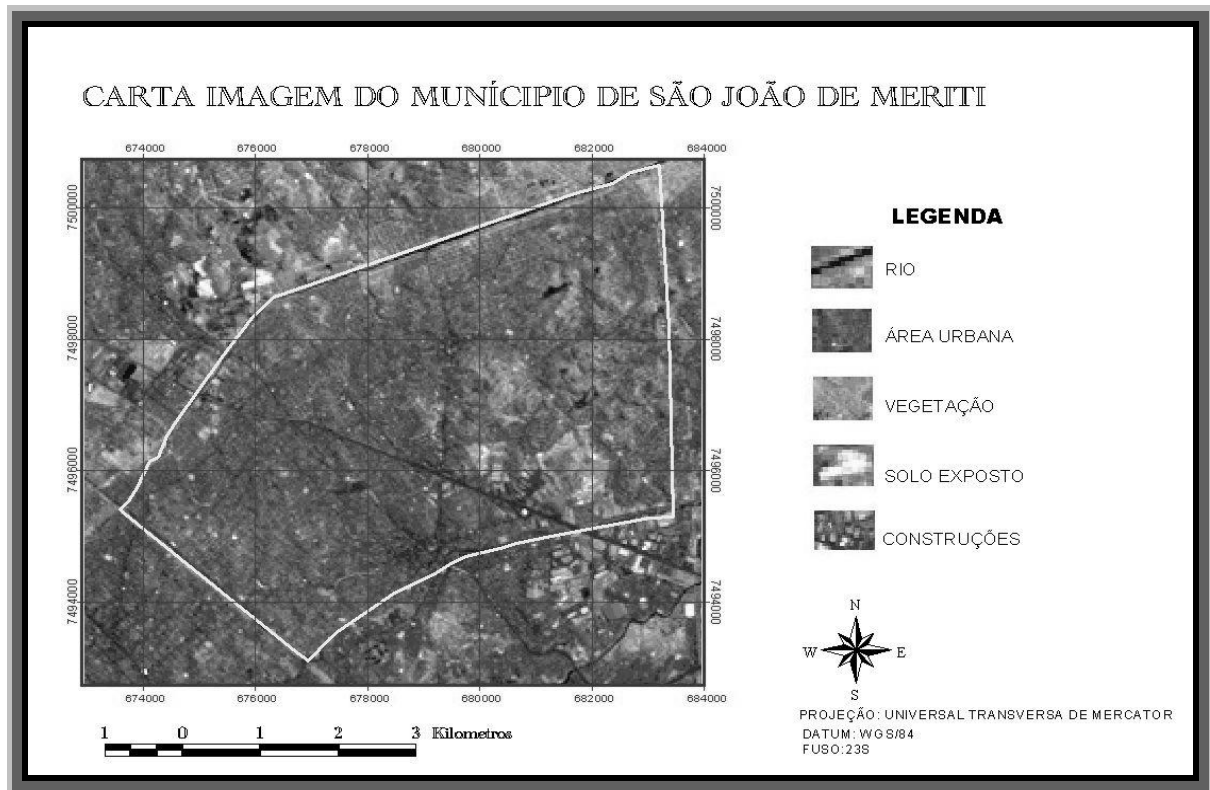

Figura 6. Carta Imagem do Município de São João de Meriti

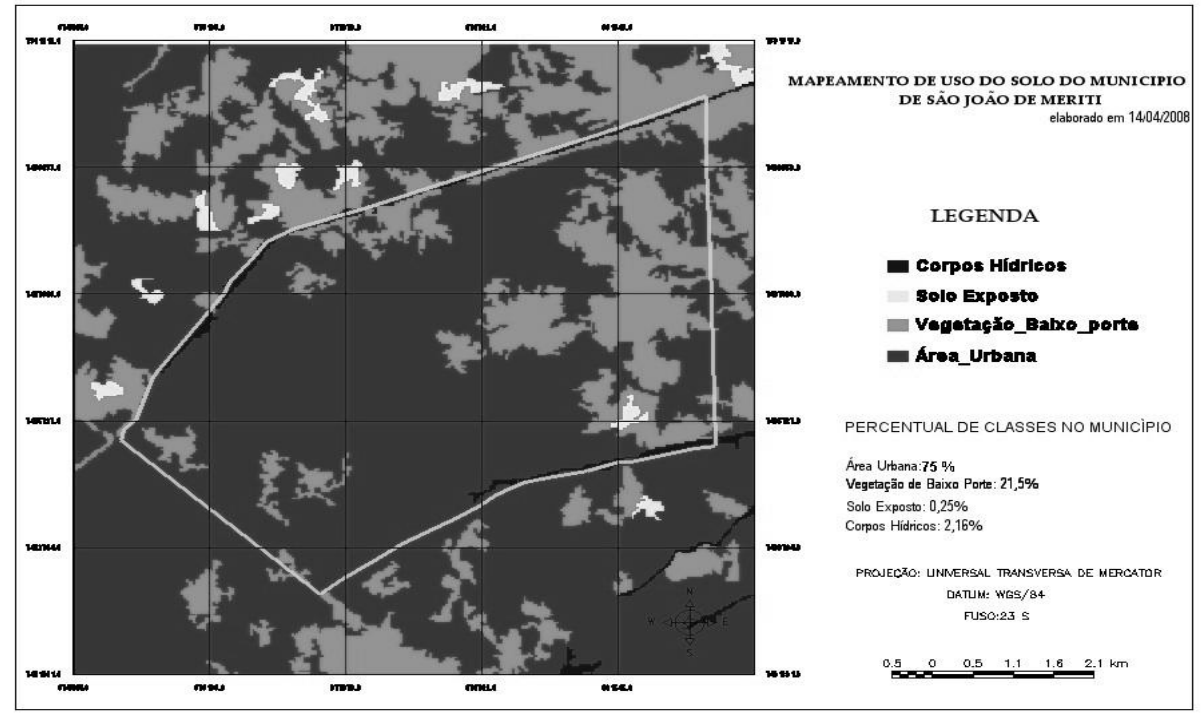

Figura 7. Mapa de Uso do Solo do município de Sâo João de Meritix

Para a obtenção da temperatura aparente na imagem termal (figura 8) foi necessária a transformação do sinal digital, proveniente do satélite, em radiância, a qual foi convertida em temperatura como descrito por Chander e Markhann (2000) pelas fórmulas a seguir:

$$
\begin{gathered}
L=\left\{\left[\left(L_{\max }-L_{\max }\right) /\left(N C_{\max }-N C_{\min }\right)\right]^{*}\left(N C-N C_{\min }\right)\right\}+L_{\min } \\
\operatorname{Temp}\left({ }^{\circ} C\right)=\left\{k_{1} /\left[\ln \left(k_{2} / L\right)+1\right]-273,15\right.
\end{gathered}
$$


Onde Lmax e Lmin representam, respectivamente, os valores da radiância máxima e mínima escalonados pelo sensor, Ncmax e $\mathbf{N c m i n}$ representam, respectivamente, os níveis de cinza máximo e mínimo, NC representa o nível de cinza de cada pixel da imagem, $\boldsymbol{k 1}(1260,56)$ e $\boldsymbol{k} \mathbf{2}$ $(607,76)$ são as constantes de calibração para a banda 6 .

Analisando a figura 6 pode-se observar que a temperatura apresenta-se bastante elevada, com uma média de $35^{\circ} \mathrm{C}$, com a ocorrência dos valores máximos, nas áreas urbanizadas (ver figuras 6 e 7) enquanto os valores mais baixos se encontram nas áreas que detêm os índices mais expressivos de vegetação, na parte leste do município, onde há uma maior concentração de morrotes ainda pouco ocupados. Por se tratar de vegetação de baixo porte (herbáceas e arbustivas) não constitui um fator de grande eficiência na amenização do forte calor.

Chama-se atenção que as áreas com temperatura superior a $39^{\circ} \mathrm{C}$ correspondem, justamente, os locais onde há galpões de fábricas, supermercados ou outras atividades industriais, o que demonstra como o uso de certos materiais e as atividades industriais exportam grande quantidade de calor para o ambiente, se refletindo no aumento da temperatura do ar e, conseqüentemente, no aumento do desconforto térmico.

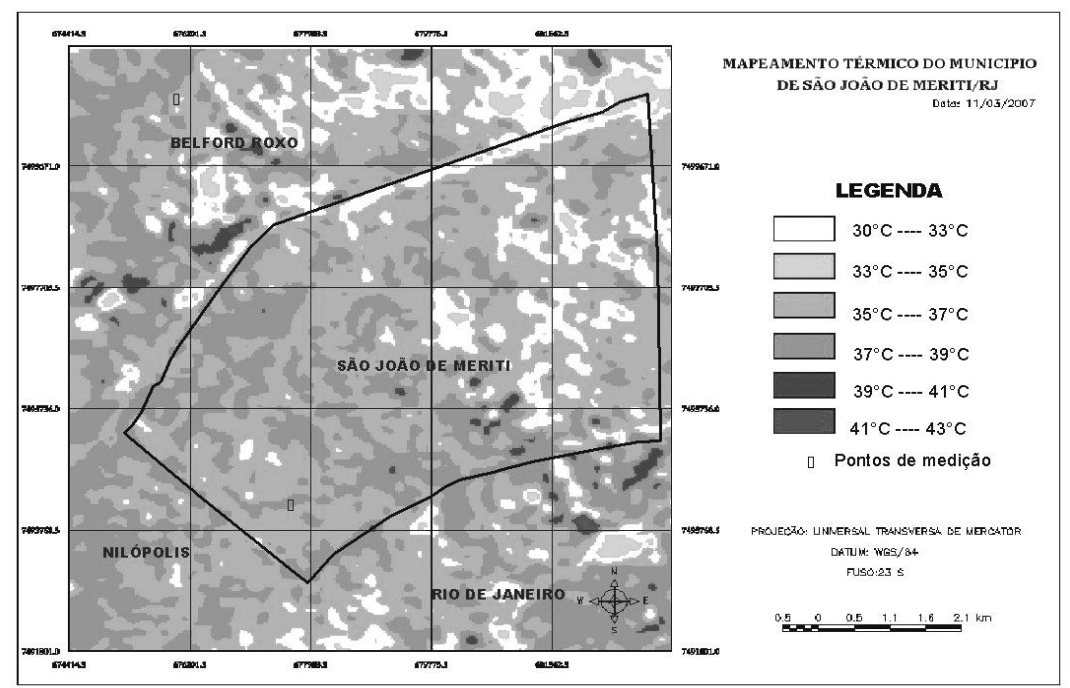

Figura 8. Mapa de Termal do município de São João de Meriti

Comparando os valores de temperatura registrados pelos equipamentos em campo as 10:00 (horário de imageamaento do Landsat) (gráficos 4 e 5) observa-se que em São João a temperatura apresentou-se $2,5^{\circ} \mathrm{C}$ mais quente que em Belford Roxo, o que demonstra como um sítio onde há maior densidade de construção favorece a uma maior retenção de calor e menor circulação do ar, o que contribui para aumentar a temperatura e intensificar a intensidade da ilha de calor.

Comparando agora os dados registrados pelos equipamentos com a imagem termal (figura 8) a temperatura estimada pelo sensor ficou acima daquela registrada nos equipamentos, onde em São João ficou na faixa de $37^{\circ} \mathrm{C}$ a $39^{\circ} \mathrm{C}$ e em Belford Roxo entre $35^{\circ} \mathrm{C}$ a $37^{\circ} \mathrm{C}$, o que já era esperado. Apesar dessa diferença, o fato mais significativo nesta comparação é que em ambas as 
ferramentas (experimento de campo e imagem termal) os resultados convergem para o mesmo ponto: o core da ilha de calor é localizado em São João de Meriti.

Acresce o fato de que nas áreas com grande circulação de pessoas e veículos a temperatura é bem mais elevada do que nas áreas mais periféricas, conforme já revelado através do experimento de inverno.

Fica assim evidente que o uso de sensores remotos é de grande utilidade ou, talvez, imprescindível para os estudos de climatologia urbana, porém a investigação de campo não pode deixar de ser realizada em hipótese alguma. Neste caso, especificamente, embora a imagem termal seja de grande valia, este sensor tem limitações como o número que bandas, que não permite discretizar os materiais existentes em cada pixel e assim á feita uma média da temperatura dos materiais no pixel. Além disso, a resolução espacial da banda 6 é de 160 metros, ou seja, cada pixel corresponde a uma área de $160 \times 160$ metros, implicando em prejuízos por conta dessa generalização.

Por tais razões o mais recomendável seria a utilização dos dois métodos de avaliação do campo térmico para configuração de ilhas de calor.

Gráfico 4. Temperatura no dia 11/03/2007 no Bairro São Mateus em São João de Meriti

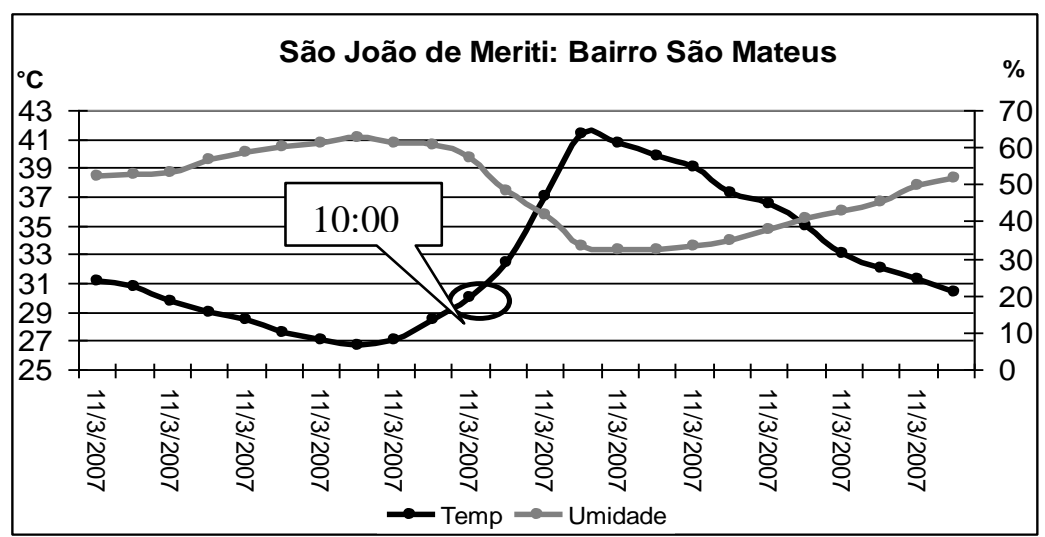

Gráfico 5. Temperatura no dia 11/03/2007 no Município de Belford Roxo

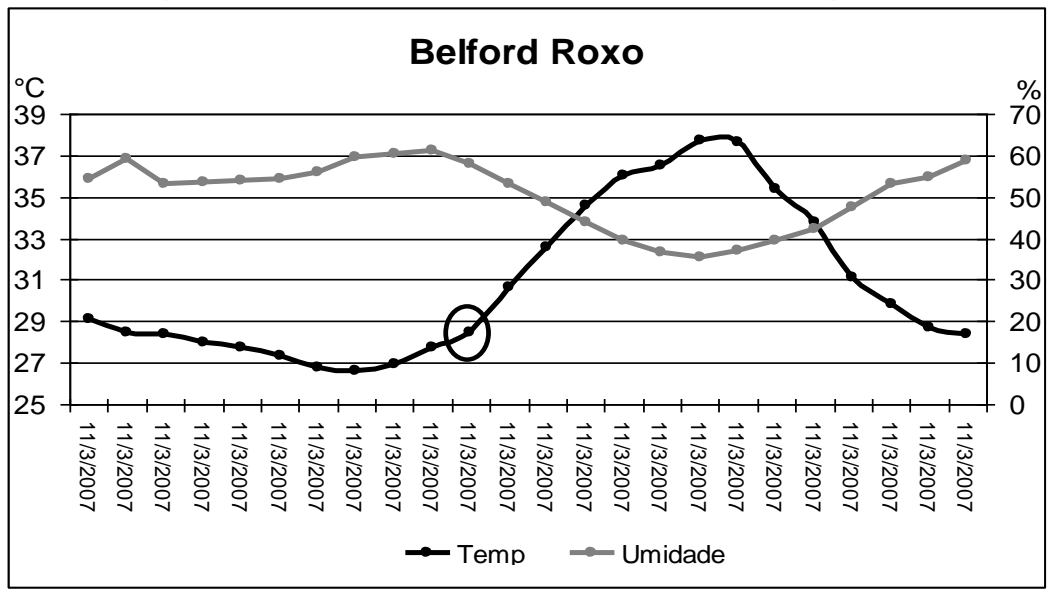




\section{CONSIDERAÇÕES FINAIS}

Com esta pesquisa pode-se constatar que as transformações ambientais no município de São João de Meriti contribuíram, decisivamente, para a configuração do seu clima local e, especialmente, do seu campo térmico atual. Fica claro que mesmo a cidade não tendo uma verticalização intensa, a grande densidade de construções somada a quase ausência de áreas verdes, representam fatores propícios a configuração de ilhas de calor, as quais podem ser agravadas em intensidade, quando as situações sinóticas se manifestam favoravelmente a tal fenômeno.

Acrescente-se que as altas temperaturas aliadas aos altíssimos índices de poluição do ar, característicos no município, além de causarem grande desconforto trazem, também, prejuízos a saúde da população.

Diante dessa situação preocupante, é necessário que o poder público, nas diversas esferas, invista em infra-estrutura e equipamentos imprescindíveis para garantir o diagnóstico básico ao planejamento municipal e necessário à implantação de ações visando à melhoria da qualidade ambiental do cidadão e, ao mesmo tempo, a minimização dos gastos com saúde, por exemplo.

Por fim, embora com algumas limitações como a baixa resolução espacial, além de poucas bandas para se obter uma melhor discretização dos objetos e da carência de modelos de correção atmosférica, como já apontados anteriormente, o uso do sensor termal do Landsat se mostrou eficaz e uma importante ferramenta para estimar a temperatura, principalmente, como meio de confrontar com a verdade terrestre, ou mesmo, para os casos em que não há disponibilidade de equipamentos para medidas diretas no campo.

\section{REFERÊNCIAS}

ABREU, M.A. (1987) . Evolução urbana do Rio de Janeiro. IPP Rio de Janeiro-RJ, 147p.

BRANDÂO, A.M.P.M. As Alterações Climáticas na área Metropolitana do Rio de Janeiro: uma provável influência do crescimento urbano IN: ABREU, Maurício de Almeida. Natureza e Sociedade do Rio de Janeiro Rio de Janeiro.1992

(1996). O Clima Urbano da Cidade do Rio de

Janeiro.Departamento de Geografia, FFLCH, USP.Tese de Doutorado. São Paulo-SP 362pp

(2003). O Clima Urbano da Cidade do Rio de Janeiro. IN: Clima Urbano. São Paulo-SP.2003. Org por MENDONÇA, F; MONTEIRO, C.A.F. Contexto USP São Paulo-SP, pp.121-154

(1987). Tendências e Oscilações Climáticas na

Área Metropolitana do Rio de Janeiro. Departamento de Geografia, FFLCH, USP.Dissertação de Mestrado. São Paulo-SP 319 pp

COSTA, H.; WILFRIED, T. (2001) Enchentes no Estado do Rio de Janeiro Uma Abordagem Geral SEMADS Rio de Janeiro-RJ, $160 \mathrm{p}$ 
LUENGO, F. (1998). Elementos para la definición y evaluación de la calidad ambiental urbana. Uma propuesta teórico-metodológica. En: IV Seminario latinoamericano de calidad de vida urbana Tandil,Argentina.

MAZZETO, F. A. P. Qualidade de vida, qualidade ambiental e meio ambiente urbano: breve comparação de conceitos. IN: Sociedade e Natureza (Revista do Instituto de Geografia da UFU). Uberlândia: EDUFU, Ano 12, n 24 - Jul/dez 2000, p. 21-31.

MENDONÇA, F.; MONTEIRO, C.A.F.(org)(2003) Clima Urbano Contexto São Paulo-SP, 192 p18

MONTEIRO, C.A.F (1990). Adentrar a cidade para tomar-lhe a temperatura. Geosul ( Revista do Departamento de Geografia da UFSC), ano 5 n9

(1990). O campo térmico na cidade de Florianópolis: primeiros experimentos Geosul (Revista do Departamento de Geografia da UFSC), ano 5 n॰9

(1976). Teoria e Clima Urbano. IGEOG-USP, Instituto de Geociências, USP, Série Teses e Monografias, 25, São Paulo, 181 pp

PEREIRA, G; MOARES, E.C; ARAÙ,E; FERREIRA,N.J. Estimativas de alterações do albedo de superfície e da emissão de gases do efeito estufa em áreas queimadas inferidas através de imagens Landsat. Anais XIII Simpósio Brasileiro de Sensoriamento Remoto, Florianópolis, Brasil, 21-26 abril2007, INPE, p. 4527-4534.

PERES,G.(1993). Os Caminhos do Ouro. Register Duque de Caxias-RJ, 70 p 